\title{
Study on wear mechanisms in drilling of Inconel 718 superalloy
}

\author{
Y.C. Chen*, Y.S. Liao \\ Department of Mechanical Engineering, National Taiwan University, Taipei, Taiwan, ROC
}

\begin{abstract}
The wear mechanisms and the approach to prolong the service life of the TiAlN coated carbide tool in drilling Inconel 718 superalloy are presented. It is found that the coated layer on the cutting edge is gradually abraded-off at the first stage of drill wear due to an excessive friction force on the tool-work interface. This in turns intensifies the friction force and leads to an increase of drilling force. Built-up edge (BUE) is then formed, and chipping starting from the relatively weaker cutting edge takes place subsequently. As a result, many micro-cracks are observed to distribute over the worn area. The subsurface fatigue cracks grow as the drilling process is proceeding. Together with the abrasion of hard carbide particles of the work material, the cutting edges break eventually parallel to the direction of fatigue cracks. At this moment, longer chip forms and cutting process is disturbed to an extent that the process can no longer be effectively continued. Failure of the drill is noted in a very short period of time once the long chips are observed. Finally, drilling experiments with the use of the cutting fluid containing the nano-particle low friction surface modifier are conducted. It is found that the service life of the drill is lengthened significantly and hence the machining cost can be greatly reduced.
\end{abstract}

(C) 2003 Elsevier B.V. All rights reserved.

Keywords: Drilling; Wear mechanisms; Inconel 718

\section{Introduction}

Nickel-base superalloy Inconel 718 is a high-temperature, precipitate-hardening alloy. Because of its excellent mechanical properties at low and intermediate temperatures $\left(-250\right.$ to $\left.700^{\circ} \mathrm{C}\right)$, it has been widely applied in recent years in aerospace, petroleum and nuclear energy industries. In machining Inconel 718 alloy, it is well known that the tool temperature rises easily due to its poor thermal properties. Micro-welding at tool-tip and chip interface takes place leading to the formation of built-up edge (BUE). The excellent material toughness results in difficulty in chip breaking during the process. In addition, precipitate hardening of $\gamma^{\prime \prime}$ secondary phase $\left(\mathrm{Ni}_{3} \mathrm{Nb}\right)$ together with work-hardening during machining makes the cutting condition even worse. All these difficulties lead to serious tool wear and less material remove rate (MRR) [1,2].

Hole making has long been recognized as one of the most prominent machining processes in aerospace manufacturing. But research of machining Inconel 718 alloy in the past was mainly on turning and milling operations [1-4], and the literature on drilling operation is very limited so far. The appropriate working range for the point angle should be greater

\footnotetext{
* Corresponding author. Fax: +886-2-2366-0443.

E-mail address: d88522022@ms88.ntu.edu.tw (Y.C. Chen).
}

than $130^{\circ}$ and it is between $5^{\circ}$ and $10^{\circ}$ for clearance angle in machining nickel-base alloy [5]. Drilling of stainless steel which has similar material properties with nickel-base alloy indicated that the dominant failure modes of the worn drills are flank wear and margin wears [6-8]. Nonetheless, detailed tool wear mechanism has not been presented in these papers. The TiAlN PVD coated tool has been proved to be effective in drilling hard materials [9-11]. However it has not been tested in drilling Inconel 718 alloy. Hence the purpose of this paper is to investigate the wear mechanism of coated tool in drilling Inconel 718, from which an attempt is made to see if the service life of the drill can be improved.

\section{Experiments}

A V65 machining center built by the Victor Taichung Machinery, Taiwan was employed to drill $30 \mathrm{~mm}$ depth holes on solid solution Inconel 718. The multi-layer TiAlN PVD coated tungsten carbide twist drills of a diameter of $10.5 \mathrm{~mm}$ made by Guhring were chosen as cutting tools. Fig. 1 shows the end view of the drill. Each cutting edge is composed of a curve edge near the periphery and a straight edge near the chisel edge for better chip breaking. Preliminary experiments were conducted to determine the optimum point and 


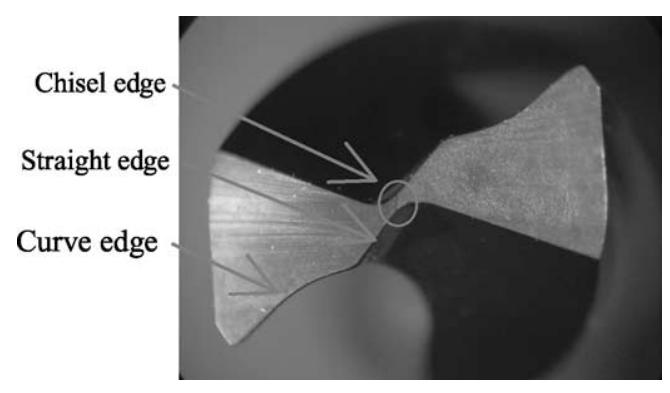

Fig. 1. End view of a drill used in the experiments.

clearance angles in drilling Inconel 718. The number of holes that can be drilled by the drill of various point angles and clearance angle are shown in Fig. 2(a) and (b), respectively. It can be readily seen that the drill of $140^{\circ}$ point angle and $8^{\circ}$ clearance angle results in better performance. Hence, they are kept unchanged throughout subsequent experiments.

A Kistler type 9273 dynamometer was set under the workpiece fixture to record the torque and thrust force during the process. These two quantities referred hereafter in the paper is the average value unless they are specified specifically. Special care is taken to ensure that a new drill is used for each test. The cutting fluid free of nitrites, phenols and chlorine was applied in all experiments. In order that the chip can be removed smoothly, pecked-drilling by lifting the drill once every $5 \mathrm{~mm}$ depth of drilling is taken for all tests. The cutting speed and feed are $400 \mathrm{rpm}(13.2 \mathrm{~m} / \mathrm{min})$ and $40 \mathrm{~mm} / \mathrm{min}(0.1 \mathrm{~mm} / \mathrm{rev})$, respectively.

During the experiment, optical microscope (OM) and scanning electronics microscope (SEM) were used to inspect tool wear condition. The related cutting properties such as hole diameter, surface roughness and material hardness were measured simultaneously as well. The relationship between the chip type, drilling force and wear were analyzed at each stage of tool wear.

Hole No.

(a)

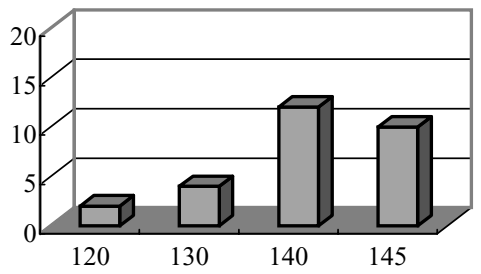

Hole No.

(b)

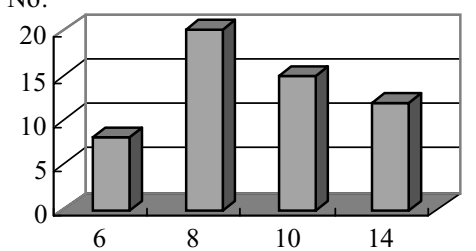

Fig. 2. Tool life with respect to drill angles: (a) point angle; (b) clearance angle.

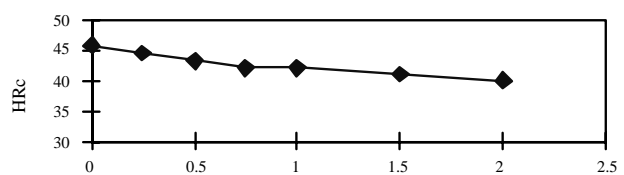

(a)

$\mathrm{mm}$

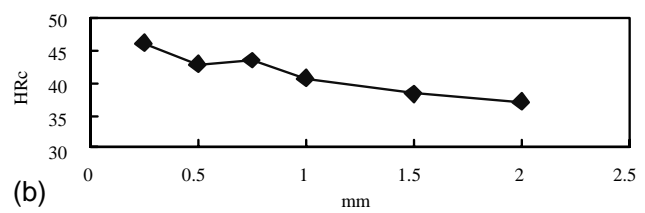

Fig. 3. Hardness measured around the hole: (a) along the depth of the hole; (b) along the radial direction of the hole.

\section{Results and wear mechanisms}

The distribution of hardness around the drilled hole is tested first and the results are given in Fig. 3. The hardness is increased from $37 \mathrm{HRc}$ of the base material to $47 \mathrm{HRc}$ for both at the bottom and side wall of the hole. The hardening of work material will increase the drilling force and accelerate tool wear.

The tool wear takes place at two different parts of a drill. One is at the straight edge close to the chisel edge, and the other is at the cutting edge near periphery. Based on the observation of tool condition associated with each drilled hole, the wear can be divided into four stages and they are summarized and shown in Table 1. At stage I, coated layer is abraded out of tungsten carbide matrix of the tool starting from the cutting edge near periphery and chisel edge as shown in Fig. 4 and results in $0.1 \mathrm{~mm}$ flank wear width after five holes have been drilled. During this period, the chip is segmented type of $0.08 \mathrm{~mm}$ thickness. Thrust force and torque with respect to holes being drilled by a new tool are shown in Fig. 5. Comparing to the initial cutting force and torque, the rise of torque is significantly larger than that of the thrust force. This may infer that an excessive friction force is resulted as the coated layer is abraded-off, and it plays a very important role at the beginning stage of tool wear.

When the same tool is used to drill more holes, the friction force is increased continuously until a particular condition is reached where BUE starts to form as that in Fig. 6(a). This period is referred as stage II. Formation of BUE leads

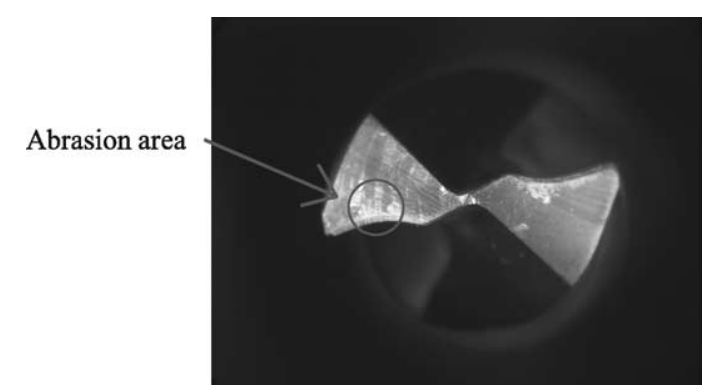

Fig. 4. Abrasion of coated layer at stage I. 
Table 1

Characteristics of drill wear at each stage

\begin{tabular}{|c|c|c|c|c|}
\hline & \multicolumn{4}{|l|}{ Stage } \\
\hline & I & II & III & IV \\
\hline \multicolumn{5}{|l|}{ Tool wear } \\
\hline \multicolumn{5}{|l|}{ Chip types } \\
\hline Descriptions & $\begin{array}{l}\text { Coated layer is abraded-off } \\
\text { (Fig. } 4 \text { ); segmented chips } \\
\text { of } 0.08 \mathrm{~mm} \text { thickness; } \\
\text { flank wear: } 0.1 \mathrm{~mm}\end{array}$ & $\begin{array}{l}\text { Chipping with } \\
\text { micro-cracks (Fig. 6); } \\
\text { larger segmented chips; } \\
\text { flank wear: } 0.2 \mathrm{~mm}\end{array}$ & $\begin{array}{l}\text { Breakage of cutting edge } \\
\text { (Fig. 8); serrated chips; } \\
\text { flank wear: } 0.3 \mathrm{~mm}\end{array}$ & $\begin{array}{l}\text { Drill failure; long chips of } \\
0.4 \mathrm{~mm} \text { thickness }\end{array}$ \\
\hline
\end{tabular}

to chipping at the weaker portion (i.e. the cutting edge near periphery) of a drill, and further loss of the coated layer. A magnified observation by using SEM reveals that there are micro-cracks distributing around the chipping area as shown in Fig. 6(b). It is also found that many carbide particles of the size of $5-10 \mu \mathrm{m}$ are deposited on the tool surface. The chipping area is enlarged in the follow-up period because of increasing abrasion of the hard particles. Fig. 7 shows the representative voltage signals of thrust force and torque in drilling measured by the dynamometer at four different stages. The discontinuous signals on the plot correspond to the interval of drill lifting in pecked-drilling. The variation of torque shown in Figs. 5 and 7(b), respectively, tends to become smoother than that of the preceding stage. Hence the process is considered stable. The flank wear is measured as well and a value of $0.2 \mathrm{~mm}$ width is obtained at this stage.

As drilling is proceeded to stage III, the flow stress causes the cracks on the chipping region to propagate towards the center of the drill. Fig. 8(a) shows the SEM photography of the subsurface cracks. They are $100 \mu \mathrm{m}$ beneath the cutting edge and grow perpendicular to the cutting direction. The cutting edge breaks instantaneous and become irregular as

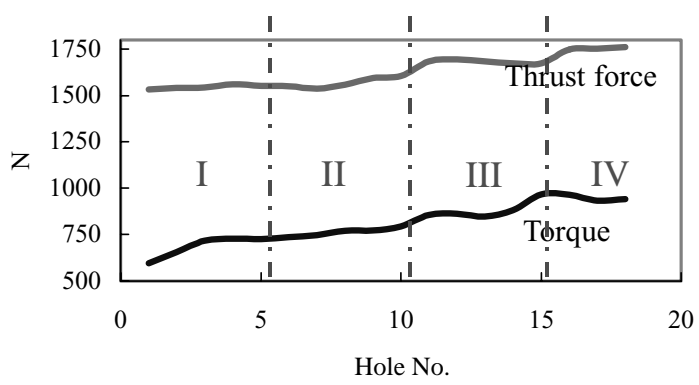

Fig. 5. Variation of thrust force and torque in drilling within the service life of a drill. shown in Fig. 8(b). The flank wear of up to $0.3 \mathrm{~mm}$ width is noted at this stage. The trace of crater wear due to the breakage of the cutting edge can also be seen on the flute of the drill as shown in Fig. 8(c). The damage of cutting edge affects the function of chip breaking and results in the formation of long and serrated chip. This in turns leads to an enormous fluctuation of torque as shown in Fig. 7(c).

Stage IV is characterized by serious flank and crater wears. At this stage the wear rate increases drastically as depicted by the increase of flank wear near the end of tool life given in Fig. 9. The chip of a thickness up to $0.4 \mathrm{~mm}$ is observed since cutting action is now replaced by extrusion. The long thick chips will tangle around the drill and tool holder, and disturb the cutting process. The variations of both thrust force and torque shown in Fig. 7(d) all reveal
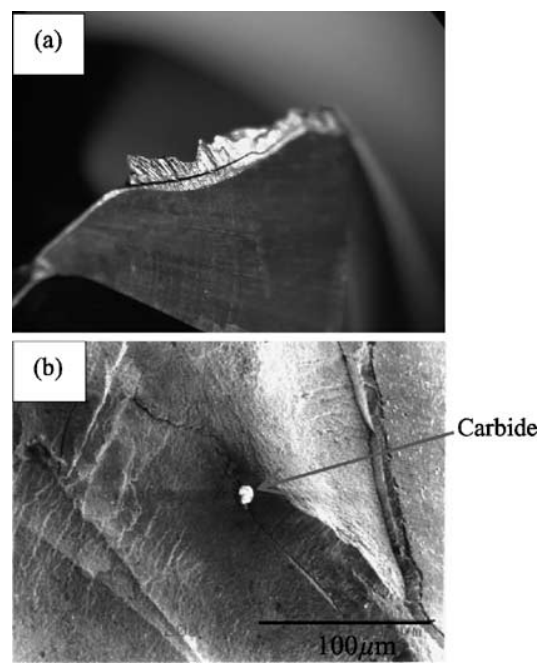

Fig. 6. Wear features during stage II: (a) formation of BUE at cutting edge; (b) micro-cracks and carbides on tool on chipping area. 


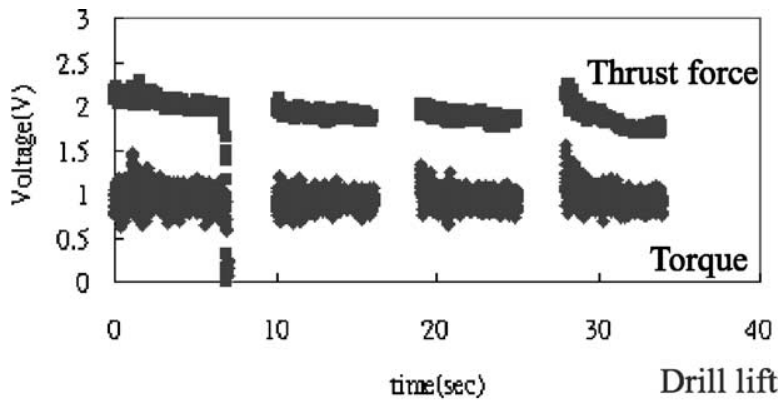

(a)

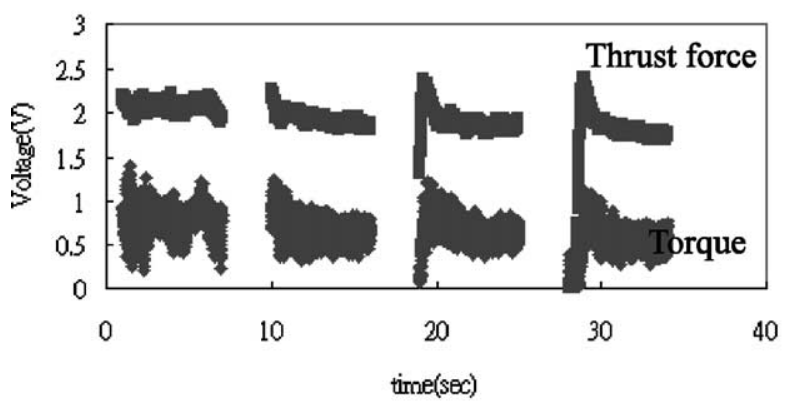

(c)

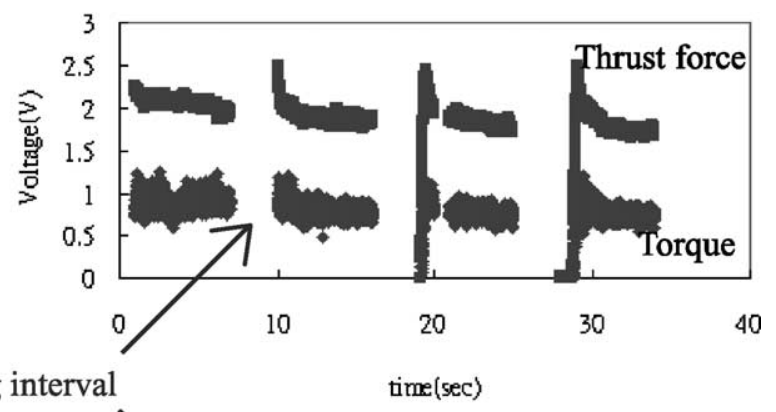

(b)

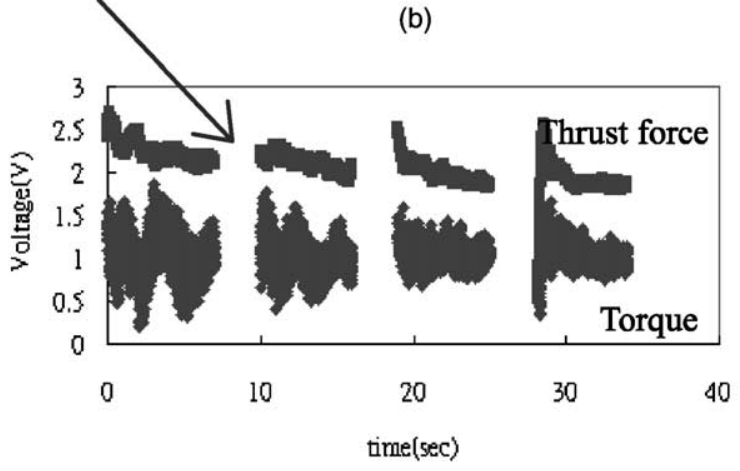

(d)

Fig. 7. The change of thrust force and torque in drilling one hole: (a) stage I; (b) stage II; (c) stage III; (d) stage IV.
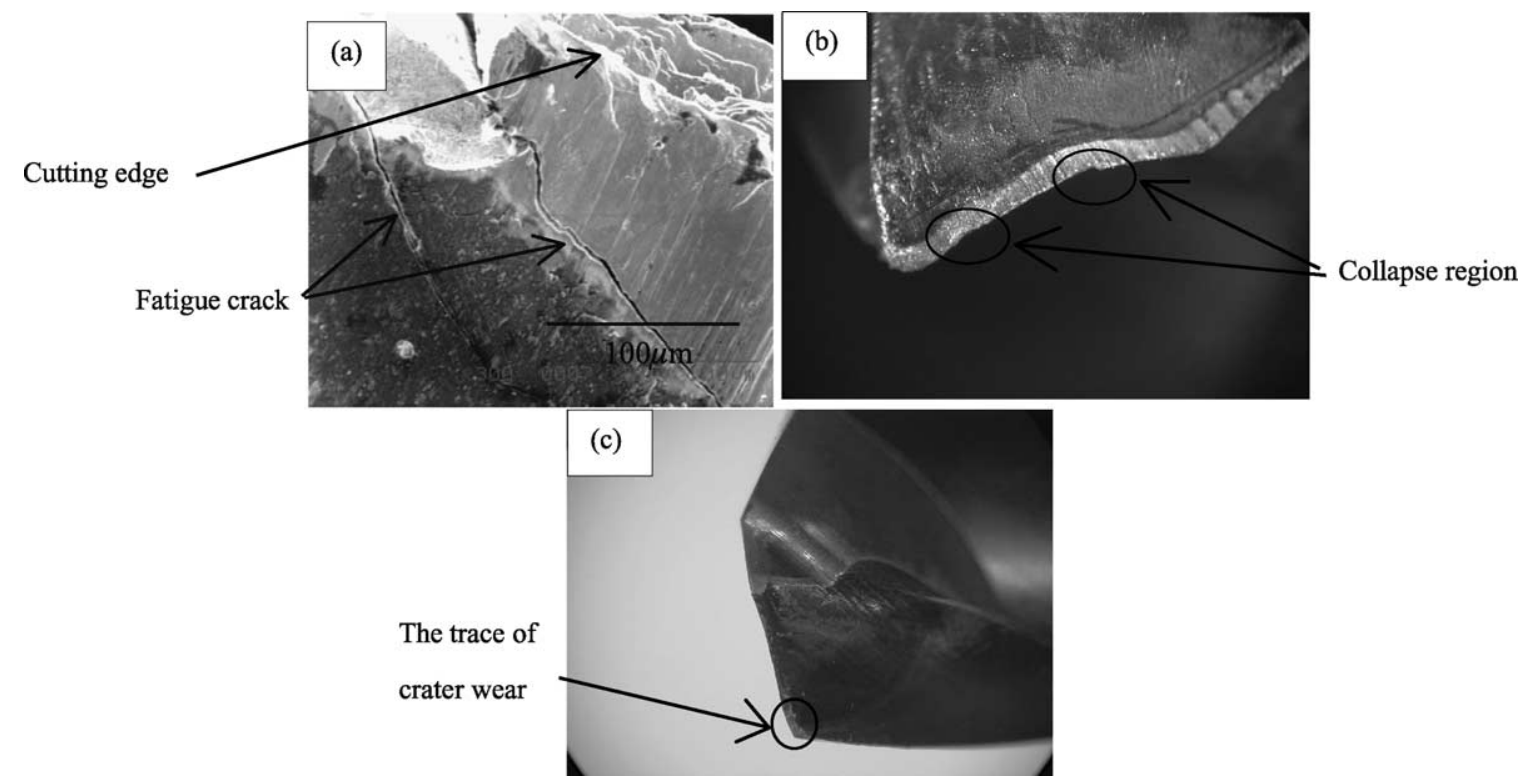

Fig. 8. Wear observation at stage III: (a) subsurface crack parallel to cutting edge; (b) breakage of cutting edge; (c) side view of the drill flute.

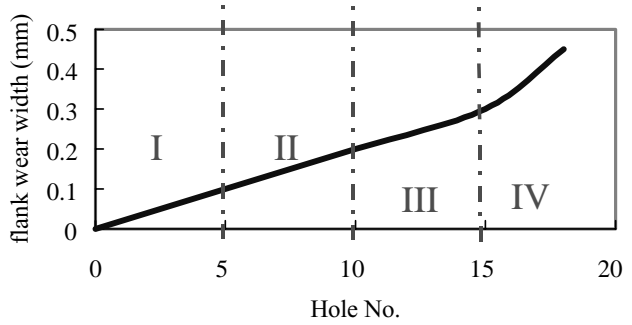

Fig. 9. Flank wear vs. tool life of the coated drill. that critical condition has been reached. It is recommended to stop the drilling process at this moment.

\section{Nano-modifier fluid}

Experiments to test the service life of the uncoated drill were carried out as well. Fig. 10(a) shows the life of coated and uncoated carbide drills when the traditional cutting fluid is applied. The usable life (in terms of holes can be drilled) 


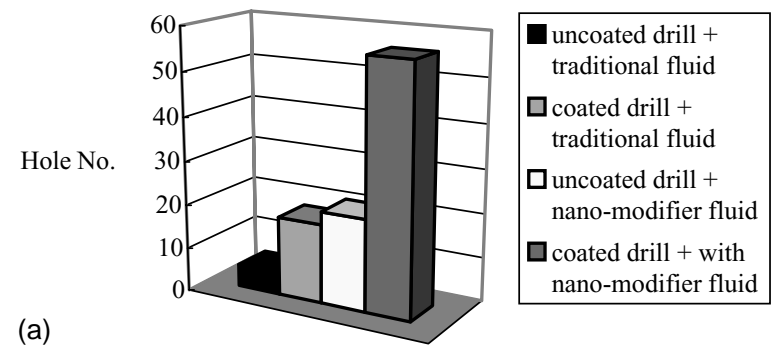

(a)

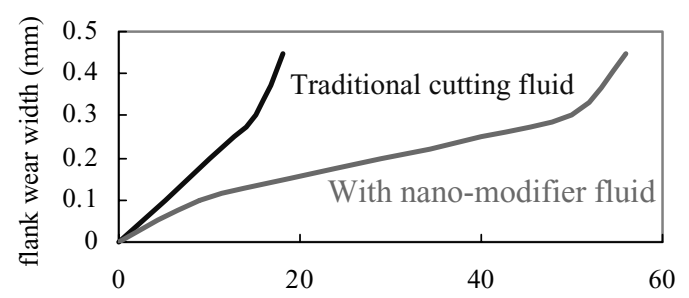

(b)

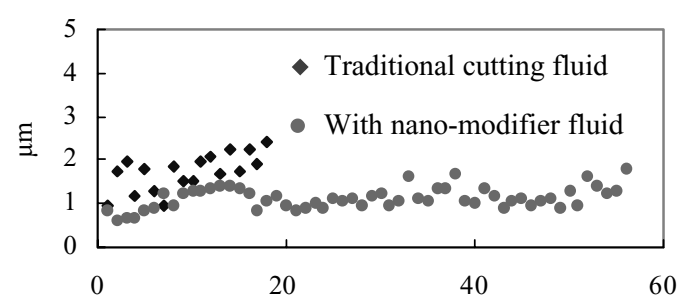

(c)

Hole No.

Fig. 10. Comparison of drilling performance when different cutting fluids was applied: (a) tool life of various tools; (b) time variation of flank wear; (c) surface roughness.

is noted to be significantly shorter for uncoated tool than that of a coated tool. This is similar to the coated drill when the coated layer is abraded-off at stage I. Hence, the primary task under consideration to prolong the drill life is to low down the friction force. In recent years, nano-technology has been applied in various fields owing to its special features. By taking the advantage of low friction of nano-particles with contacting surface, drilling experiments by applying the cutting fluid mixed with sufficient amount of nano-particles were conducted.

In the experiment, the water-soluble nano-particle surface modifier provided by Energy Release, USA, was used. The size of the particles is $5-23 \mathrm{~nm}$. For comparison purpose, the resulted drill life is given in Fig. 10(a) as well. It is clear from the figure that the drill life has been prolonged by more than three times when nono-modifier fluid was applied. The flank wear width vs. number of holes being drilled is shown in Fig. 10(b). It can be seen from this figure that the flank wear width is $0.2 \mathrm{~mm}$ when a drill reaches two-third of its usable life with the use of traditional cutting fluid, while there is only $0.1 \mathrm{~mm}$ flank wear width when the nano-modifier fluid is used. Based on above results, it is conjectured that the action of the nano-modifier is seemed to induce the formation of a thin film on both tool and work surfaces due to its high bonding force with the contacting surface. This in turns reduces the real area of contact between tool and work, and hence friction force is decrease as a result. The governing mechanism of tool wear is postponed to occur, and accordingly drill life is increased.

Comparison of the surface roughness of the hole being drilled is given in Fig. 10(c). The deterioration of surface roughness is greatly improved with the application of nano-modifier fluid as expected.

It is also noted from Fig. 10(a) that the use of uncoated carbide drill and nano-modifier fluid results in even better drill life than the use of coated carbide drill and traditional cutting fluid. Hence it is a compromise alternative if both machining efficiency and cost are taken into account in drilling Inconel 718 alloy.

\section{Conclusion}

The wear mechanisms in drilling Inconel 718 alloy by coated carbide tool are investigated. Friction force is found to be the most important factor governing tool failure. Wear mechanisms can be classified into four stages. The coated layer is abraded-off first. It is followed by flank wear, and chipping at the outer cutting edge. The micro-cracks around the region of chipping propagate and lead to subsurface fatigue cracks. This together with crater wear causes the failure of a drill eventually. The use of cutting fluid mixed with nano-particles in drilling Inconel 718 alloy can effectively reduce friction force and triple the tool life.

\section{References}

[1] M. Rahman, W.K.H. Seah, T.T. Teo, The machinability of Inconel 718, J. Mater. Process. Technol. 63 (1997) 199-204.

[2] I.A. Choudhury, M.A. El-Baradie, Machinability of nickel-base super alloys: a general view, J. Mater. Process. Technol. 77 (1998) 278-284.

[3] L.N. Lopez de lacalle, J. Perez, J.I. Llorente, J.A. Sanchez, Advanced cutting conditions for the milling of aeronautical alloys, J. Mater. Process. Technol. 100 (2000) 1-11.

[4] E.O. Ezugwu, Z.M. Wang, Wear of coated carbide tools when machining nickel (Inconel 718) and titanium base (Ti-6Al-4V) alloys, Tribol. Trans. 43 (2000) 263-268.

[5] ASM Handbook Committee, Machining Handbook, American Society for Metals, Metals Park, OH, 1989.

[6] E.O. Ezugwu, C.J. Lai, Failure modes and wear mechanisms of M35 high speed steel drills when machining Inconel 901, J. Mater. Process. Technol. 49 (1995) 295-312.

[7] W.C. Chen, K.H. Fuh, The cutting performance of a TiN-coated drill with curved primary cutting edges, J. Mater. Process. Technol. 49 (1995) 183-198.

[8] B. Mubaraki, S. Bandyopadhyay, R. Fowle, P. Mathew, Drilling studies of an $\mathrm{Al}_{2} \mathrm{O}_{3}-\mathrm{Al}$ metal matrix composite. Part I. Drill wear characteristics, J. Mater. Sci. 30 (1995) 6273-6280.

[9] P.C. Jindal, A.T. Santhanam, U. Schleinkofer, A.F. Shuster, Performance of PVD TiN, TiCN, and TiAlN coated cemented carbide tools in turning, Int. J. Refract. Met. Hard Mater. 17 (1999) 163-170.

[10] K. Tonshoff, A. Mohlfeld, T. Leyendecker, H.G. Fuß, G. Erkens, R. Wenke, T. Cselle, M. Schwenck, Wear mechanisms of $\left(\mathrm{Ti}_{1-x}, \mathrm{Al}_{x}\right) \mathrm{N}$ coating in dry drilling, Surf. Coat. Technol. 94-95 (1997) 603-609.

[11] M. Berger, S. Hogmark, Tribological properties of selected PVD coatings when slid against ductile materials, Wear 252 (2002) 557-565. 